\title{
Retention of Helping Babies Breathe Training among Midwives and Nurses at Four Rwandan Health Centers
}

\author{
Felicite Kankindi ${ }^{1 *}$, Alice Muhayimana ${ }^{1}$, Patricie Mujawimana ${ }^{1}$, Ruth Dusabe ${ }^{1}$, Richard \\ Nsengiyumva $^{1}$, Madeleine Mukeshimana ${ }^{1}$ \\ ${ }^{1}$ University of Rwanda, College of Medicine and Health Sciences, Kigali, Rwanda
}

*Corresponding author: Félicité Kankindi. School of Nursing and Midwifery, College of Medicine and Health Sciences, University of Rwanda, Huye Campus, South Province, Rwanda. Email: kankifeli@gmail.com.

\begin{abstract}
\section{Background}

Worldwide, neonatal mortality remains a significant burden. One substantial cause of mortality is asphyxia, where neonates fail to breathe on their own at birth and need some form of assistance to initiate or maintain breathing. The Helping Babies Breathe (HBB) training program has proven to be helpful in the reduction of asphyxia-related neonatal mortality in developing countries.
\end{abstract}

\section{Objective}

To assess the HBB knowledge and skills retention at two-days and six-weeks post HBB training among midwives and nurses working in selected health centers in Kigali, Rwanda.

\section{Methods}

A quasi-experimental design with a pre-test, post-test, and intervention using HBB (2 ${ }^{\text {nd }}$ Edition) program was used. Sixty midwives and nurses were purposively selected from the four study sites. Knowledge and skills retention of HBB was evaluated at two-days and six-weeks posttraining.

\section{Results}

The majority of participants were nurses (90\%), females (70\%), and had advanced diploma (63\%). Knowledge overall mean scores improved from pre-test (8.75) to post-test (16.90). Skills mean scores slightly dropped from 21.77 at day two to 19.73 ).

\section{Conclusion}

Our results indicated that there was retention of knowledge and skills among the midwives and nurses at day two and six-weeks post HBB training. Refresher training programs are needed to keep providers skilled for resuscitation in order to lower neonatal mortality in Rwanda.

Rwanda J Med Health Sci 2020;3(2):250-260

Keywords: Helping Babies Breathe, knowledge and skills retention, midwives and nurses 


\section{BACKGROUND}

Many neonatal deaths that occur within the first 28 days could be prevented with quality care at birth, or skilled care and treatment offered immediately after birth.[1] The first 28 days, known as the neonatal period, is the most vulnerable for a child with an average global mortality rate of 18 deaths per 1,000 live births.[2]Sub-Saharan Africa (SSA) has the highest neonatal mortality rate of 28 deaths per 1,000 live births, which is 10 times higher than in high-income regions.[2] In addition, about 2.6 million were stillborn.[1] Neonatal mortality is predominately caused by preterm birth, infections, and intra-partum events, such as asphyxia, where neonates fail to breathe on their own at birth and need some form of assistance to initiate or maintain breathing.[2]

Asphyxia is related to an antenatal, labor and delivery, or postnatal condition and one of the early primary causes of neonatal mortality.[3] Approximately 2.7 million neonatal deaths occur worldwide per year, and an estimated $25 \%$ are due to asphyxia.[4] Asphyxia, derived from the Greek word meaning pulseless, is caused by a compromised placental or respiratory gas exchange, leading to low oxygen and cardio- respiratory depression.[3] Asphyxia is the most common cause of hypoxic-ischemic encephalopathy (HIE), an acute brain injury with high mortality or long-term neurological disability.[3] A recent study in Rwanda showed that $39.5 \%$ of newborns admitted to an urban district hospital Neonatal Intensive Care Unit (NICU) had asphyxia.[5] A recent audit in Rwanda showed that $60 \%$ of neonatal mortality deaths are potentially preventable.[6] Understanding the causes of neonatal deaths allows identifying interventions that will reduce mortality.

A life-saving training program known as Helping Babies Breathe (HBB) was initiated and developed by the American Academy of Pediatrics (AAP) in 2010 , in collaboration with the WHO, and supported by numerous other international health organizations.[7] The HBB program teaches the steps of neonatal resuscitation that healthcare providers (HCPs) need to achieve during The Golden Minute which is known as the first minute after birth. This is a critical time for the newborn to survive and potentially thrive, as they transition from fetus to newborn breathing in extra-uterine life.[7] The initial steps in the Golden Minute include drying and stimulation of the newborn, and possibly suctioning (if needed); basic interventions that should quickly bring about spontaneous respirations in $90 \%$ of newborns not breathing.[8]
Various studies have demonstrated the success of the HBB neonatal resuscitation program in developing countries. The initial study in eight hospitals in Tanzania demonstrated that the HBB techniques could reduce neonatal mortality by up to $47 \%$ and fresh stillbirths by $24 \%$.[9] In the study done in Ghana, the results showed the effectiveness of $\mathrm{HBB}$ training in decreasing the mortality rate from $1.7 \%$ to $0.7 \%$ within the first 24 hours after birth.[10] Another study conducted in South Sudan, HBB training demonstrated significant increase in knowledge and skills of HCPs, which contributed to a decreased neonatal mortality rate.[11]

In 2016, a second edition and updated HBB program was launched to help improve the quality of neonatal resuscitation.[12,28] Neonatal resuscitation is effective only when HCPs have sufficient knowledge and skills.[13] The goal of the HBB program is to teach effective care, immediately after birth, including proper drying, stimulation, clearing the airway, along with bag-mask ventilation, when required. Importantly, this lifesaving package gives these skills without teaching the advanced techniques of chest compression and medication use.[14]

However, there is variation in the retention of $\mathrm{HBB}$ knowledge and skills that have also been addressed through research. A study conducted in India and Kenya showed that skills declined more than knowledge over time, and it was recommended that ongoing skills practice and monitoring, more frequent retesting, and refresher training are needed to maintain neonatal resuscitation skills. [15] A study conducted in Rwanda revealed that HBB knowledge was retained three-months posttraining, but practical skills had deteriorated among the HCPs at two district and one tertiary hospital.[6]

HBB training can prevent neonatal mortality and improve the chances of the infant survival rate by providing knowledge and skills to health care providers.[16] However, little is known and documented on HBB's knowledge and skills retention among midwives and nurses in Rwanda. Thus, this study aimed to assess HBB knowledge and skills retention among midwives and nurses from selected health centers in Kicukiro District, Rwanda.

\section{METHODS}

\section{Design}

A quasi-experimental design was used to assess HBB knowledge and skills retention. Scores were obtained at three time-points testing; pre-training, 
two-days post-training, and at six-weeks post-training. Nurses and midwives were given a one-time HBB training session of two days (2 days) at their work sites. Four selected health centers in Kicukiro District (Bethsaida, Gahanga, Gatenga, and Kicukiro) were selected randomly. The study was conducted from March 20 to May 8, 2019.

\section{Participants' recruitment}

The purposive sampling strategy was used to recruit the study participants. Any midwife or nurse working in one of the four-selected health centers, that was available for the three testing sessions and one training session, and consented to participate, was included in the study. The sample size $(n=60)$ was based on the number of midwives and nurses available to be involved in the three training sessions at each health center study site.

\section{Measures}

The tools used in the study were the HBB training (second edition) tools developed by the AAP and WHO.[17] A questionnaire with multiple-choice questions (MCQ) was used to assess HBB knowledge. An Objective Structured Clinical Examination (OSCE) and the NeoNatalie mannequin, an inflatable simulator designed to teach basic neonatal resuscitation was used to assess HBB skills. Some slight tool adaptations were made to fit the objectives of the study and the local context of participants. The Multiple Choice Questions(MCQ) checklist (HBB, $2^{\text {nd }}$ edition) for knowledge was made of 18 knowledge questions. Then, the OSCE (HBB, $2^{\text {nd }}$ edition) for skills was made of 35 items. Therefore, we took those 26 mandatory skills and combined some, e.g. close observation of the baby, and Communicate with mother, so our OSCE skills list had 24 questions. The knowledge questionnaire and OSCE was made up of four sections:

Section one consisted of the participant socio-demographic characteristics with six items, including age, gender, education level, qualification, previous HBB training ( $1^{\text {st }}$ HBB edition), and years of work experience. Results were presented using frequencies (Table 1).

Section two consisted of the HBB (second edition) knowledge assessment (18 items). The knowledge assessment was given at three-time points; pre-test, and post-test at two-days and six weeks posttraining. These were MCQ with a choice of four possible responses (a-d). Participants were advised to "select the best answer to each question or statement, and circle the letter of the correct answer". Items with dots, participants had to fill in the right answer. The correct answer received 1 point, and an incorrect or no answer received zero points. The total score was $0-18$ points and measured in a mean score, with a standard deviation (SD), and p-value (Table 2).

Section three consisted of the skills assessment using the HBB standardized checklist (24 items). Participants were given instruction and then observed while doing the skill. The skills assessment was conducted at two-days post-training and six weeks post-training. The same scenario was set-up for both skill assessments ( 2 days, and 6 weeks) using the NeoNatalie mannequin.

A case scenario was read aloud in order to facilitate the participants' knowledge of the next steps. "You are called to assist a normal delivery of a term baby. All four antenatal visits were done, and no complications related to the pregnancy had been identified. The mother is feeling the urge to push. Provide the care. The case scenario was adapted from OSCE HBB second edition.[1] The reviewer ticked the OSCE checklist box as either "Done" (1 point), or "Not Done" (0 points) for each activity. The total score was 0-24 points.

Section four consisted of comparisons of the sociodemographic characteristics (6 items) and the knowledge and skills mean scores at six-weeks posttraining. The study tools were shared with expert midwives and nurses for face validation and confirmation that they would be measuring what they were supposed to measure in direction of neonatal resuscitation.

\section{Data collection}

Researchers contacted and notified the in-charges at health centers to assist in availability of their midwifery and nursing staff. Data collection occurred during a two-hour morning session in the staff meeting room each day at health centers for six weeks. The hours and days varied depending on staff availability. A pre-trained research assistant (RA) with over 10 years of midwifery experience was used and helped to conduct both the knowledge and skills (OSCE) assessments.

Once the participants were at the study site, the investigator explained the study in wide details and answered any questions. Then written consent was obtained prior to the pre-test assessment. To maintain confidentiality and privacy of information, participants who signed a consent form were given a code, which was used in the pre-test, two-days posttest, and six-weeks post-test. The MCQ questionnaire had to be completed in 30 minutes, and the 
HBB OSCE in seven minutes. The same questionnaire was given at all three-time points and the same OSCE at two-time points (two-days and sixweeks post-training). The investigator corrected and compiled participants' results on the day of testing.

\section{Data analysis}

Statistical Package for the Social Sciences (SPSS), Version 21, was employed for analysis. Descriptive and inferential statistics were used to analyze the data. A paired sample T-test analysis was done to compare the level of skill retention of two means (OSCE two days after training). Friedman test was used to test the mean difference between the levels of knowledge retention of more than two means (pretest, day two post-test, and six weeks follow-up test). The student t-test was used to analyze the mean difference between day two post-training skills retention and that of six weeks after the HBB training.

\section{Ethical considerations}

Ethical approval from the University of Rwanda, College of Medicine and Health Sciences Institutional Review Board (IRB): reference number 023/2019 was obtained. The permission to start data collection was obtained from the Director of
Masaka District Hospital and the in-charge at the four selected health centers. All participants signed a voluntary written consent before participating in the study.

\section{RESULTS}

Sixty participants completed the three knowledge assessments and two OSCE assessments. These included 14 nurses and 2 midwives at Bethsaida Health Center, 13 nurses and 1 midwife at Gahanga, 14 nurses and 1 midwife at Gatenga, and 14 nurses and 1 midwife at Kicukiro. A response rate was not calculated as the In-charge at each health center made the decision based on staffing needs that could be available for training.

\section{Sociodemographic characteristics of participants}

Among the 60 participants, the majority $(70 \%)$ was female, $60 \%$ of all participants were aged between 25-35 years, and 63\% had an advanced diploma. Then, the majority of participants $(90 \%)$ were nurses, about half (43.3\%) reported work experience of greater than five years, and nearly a quarter had previously received HBB training using the first edition guidelines $(21.7 \%)$ 


\section{Participants' knowledge performance in pretest, at day two post-training and at six week post training}

Table 1. Participants knowledge performance in pretest, at day two post-training and follow up at six week

\begin{tabular}{|c|c|c|c|c|c|c|}
\hline \multirow[t]{2}{*}{ Knowledge Assessment items } & \multicolumn{2}{|c|}{ Pretest answers } & \multicolumn{2}{|c|}{$\begin{array}{l}\text { Post-test at } 2 \text { days } \\
\text { post-training } \\
\text { answers }\end{array}$} & \multicolumn{2}{|c|}{$\begin{array}{l}\text { Follow up test at } 6 \\
\text { weeks post-training } \\
\text { answers }\end{array}$} \\
\hline & $\begin{array}{l}\text { Correct } \\
\mathrm{n}(\%)\end{array}$ & $\begin{array}{l}\text { Incorrec } \\
\mathrm{t} \quad \mathbf{n}(\%)\end{array}$ & $\begin{array}{l}\text { Correct } \\
\text { n (\%) }\end{array}$ & $\begin{array}{l}\text { Incorrect } \\
\text { n (\%) }\end{array}$ & $\begin{array}{l}\text { Correct } \\
\mathbf{n}(\%)\end{array}$ & $\begin{array}{l}\text { Incorrect } \\
\text { n (\%) }\end{array}$ \\
\hline $\begin{array}{l}\text { What should you do in The Golden } \\
\text { Minute? }\end{array}$ & $33(55)$ & $27(45)$ & $58(96.7)$ & $2(3.3)$ & $57(95)$ & $3(5)$ \\
\hline Which baby is breathing well & $25(41.7)$ & $35(58.3)$ & $57(95)$ & $3(5)$ & $54(90)$ & $6(10)$ \\
\hline Prepare for a birth & $24(40)$ & $36(60)$ & $58(96.7)$ & $2(3.3)$ & $54(90)$ & $6(10)$ \\
\hline Prepare area for delivery & $22(36.7)$ & $38(63.3)$ & $57(95)$ & $3(5)$ & $54(90)$ & $6(10)$ \\
\hline What should you do to keep baby warm? & $27(45)$ & $33(55)$ & $57(95)$ & $3(5)$ & $58(96.7)$ & $2(3.3)$ \\
\hline $\begin{array}{l}\text { Which baby can receive routine care } \\
\text { after birth? }\end{array}$ & $23(38.3)$ & $37(61.7)$ & $59(98.3)$ & $1(1.7)$ & $50(83.3)$ & $10(16.7)$ \\
\hline Routine care for a healthy baby at birth & $38(63.3)$ & $22(36.7)$ & $57(95)$ & $3(5)$ & $42(70)$ & $18(30)$ \\
\hline $\begin{array}{l}\text { When should cord be clamped, tied, cut } \\
\text { during routine care }\end{array}$ & $34(56.7)$ & $26(43.3)$ & $58(96.7)$ & $2(3.3)$ & $56(93.3)$ & $4(6.7)$ \\
\hline $\begin{array}{l}\text { What should you do for newborn baby is } \\
\text { quiet, limp and not crying? }\end{array}$ & $28(46.7)$ & $32(53.3)$ & $56(93.3)$ & $4(6.7)$ & $55(91.7)$ & $5(8.3)$ \\
\hline $\begin{array}{l}\text { What should you do next, if baby does } \\
\text { not respond to steps to stimulate } \\
\text { breathing? }\end{array}$ & $30(50)$ & $30(50)$ & $57(95)$ & $3(5)$ & $55(91.7)$ & $5(8.3)$ \\
\hline $\begin{array}{l}\text { In which situation should a baby be } \\
\text { suctioned }\end{array}$ & $29(48.3)$ & $31(51.7)$ & $58(96.7)$ & $2(3.3)$ & $57(95)$ & $3(5)$ \\
\hline $\begin{array}{l}\text { Suctioning a baby unnecessarily or } \\
\text { frequently can cause ... }\end{array}$ & $33(55)$ & $27(45)$ & $57(95)$ & $3(5)$ & $56(93.3)$ & $4(6.7)$ \\
\hline $\begin{array}{l}\text { Which of the following statements about } \\
\text { bag and mask ventilation is TRUE }\end{array}$ & $43(71.7)$ & $17(28.3)$ & $57(95)$ & $3(5)$ & $53(88.3)$ & $7(11.7)$ \\
\hline $\begin{array}{l}\text { Baby's chest not moving with bag and } \\
\text { mask ventilation what should you do? }\end{array}$ & $31(51.7)$ & $29(48.3)$ & $58(96.7)$ & $2(3.3)$ & $56(93.3)$ & $4(6.7)$ \\
\hline You can stop ventilation if... & $34(56.7)$ & $26(43.3)$ & $50(83.3)$ & 10(16.7) & $54(90)$ & $6(10)$ \\
\hline $\begin{array}{l}\text { A newborn baby's heart rate should be } \\
160\end{array}$ & 19(31.7) & $41(68.3)$ & $18(30)$ & $42(70)$ & $55(91.7)$ & $5(8.3)$ \\
\hline A baby who received ventilation & $26(43.3)$ & $34(56.7)$ & $60(100)$ & $0(0$ & $55(91.7)$ & $5(8.3)$ \\
\hline $\begin{array}{l}\text { When should bag, mask and suction } \\
\text { device be disinfected }\end{array}$ & $26(43.3)$ & $34(56.7)$ & $58(96.7)$ & $2(3.3)$ & $55(91.7)$ & $5(8.3)$ \\
\hline Overall Mean scores & 8.75 & & 16.90 & & & 16.27 \\
\hline$\pm \mathbf{S D}$ & 3.98 & & 1.29 & & & 1.50 \\
\hline
\end{tabular}

*Note: $S D=$ Standard deviation

*Knowledge items: Correct answer=1 point and Incorrect answer=0 point. The total score is 18

*Items with dots, participants had to fill in the right answer

The table 1 shows the pretest, post-test at day two post-training and follow up at six week participants 'performance in knowledge. The total mean score for all participants was 8.75 with the standard deviation of 3.98. Knowledge average score for the knowledge total means score and standard deviation at day two post-training was 16.90 and 1.29 respectively. At 6week post-training the mean score was 16.27 with the standard deviation of 1.50 . This results show a positive modification during the three time-points, from pre-test, post-test ( 2 days) and post-test (6 weeks) evaluation. 


\section{Participants'performance in HBB skills at day two post training and follow up at} six week

Table 2. Participants 'performance in HBB skills at day two post training and follow up at six week

\begin{tabular}{|c|c|c|c|c|}
\hline \multirow[t]{2}{*}{ Skills assessment items } & \multicolumn{2}{|c|}{$\begin{array}{l}\text { OSCE AT DAY } 2 \\
\text { POST-TRAINING }\end{array}$} & \multicolumn{2}{|c|}{$\begin{array}{l}\text { OSCE AT } 6 \text { WEEK } \\
\text { POST-TRAINING }\end{array}$} \\
\hline & $\begin{array}{l}\text { Done } \\
\text { n (\%) }\end{array}$ & $\begin{array}{l}\text { Not done } \\
\mathbf{n}(\%)\end{array}$ & $\begin{array}{l}\text { Done } \\
\text { n (\%) }\end{array}$ & $\begin{array}{l}\text { Not done } \\
(\%)\end{array}$ \\
\hline Identifies a helper and reviews an emergency plan & $53(88.3)$ & $7(11.7)$ & $43(71.7)$ & $17(28.3)$ \\
\hline Prepares the area for delivery & $56(93.3)$ & $4(6.7)$ & $46(76.7)$ & $14(23.3)$ \\
\hline Washes hands & $56(93.3)$ & $4(6.7)$ & $50(83.3)$ & $10(16.7)$ \\
\hline $\begin{array}{l}\text { Prepares area for ventilation and checks BMS } \\
\text { device }\end{array}$ & $54(90)$ & $6(10)$ & $48(80)$ & $12(20)$ \\
\hline Dries thoroughly & $57(95)$ & $3(5)$ & $49(81.7)$ & $11(18.3)$ \\
\hline Removes wet cloth & $51(85)$ & $9(15)$ & $49(81.7)$ & $11(18.3)$ \\
\hline Recognizes baby is not crying & $54(90)$ & $6(10)$ & $50(83.3)$ & $10(16.7)$ \\
\hline Positions head and clears airway & $58(96.7)$ & $2(3.3)$ & $50(83.3)$ & $10(16.7)$ \\
\hline Stimulates breathing by rubbing the back & $52(86.7)$ & $8(13.3)$ & $48(80)$ & $12(20)$ \\
\hline Recognizes baby is crying and breathing well & $52(86.7)$ & $8(13.3)$ & $48(80)$ & $12(20)$ \\
\hline Clamps or ties and cuts the cord & $58(96.7)$ & $2(3.3)$ & $50(83.3)$ & $10(16.7)$ \\
\hline Positions SSC and applies head covering & $58(96.7)$ & $2(3.3)$ & $48(80)$ & $12(20)$ \\
\hline Communicates with mother & $56(93.3)$ & $4(6.7)$ & $54(90)$ & $6(10)$ \\
\hline Recognizes baby is not breathing & $54(90)$ & $6(10)$ & $52(86.7)$ & $8(13.3)$ \\
\hline Cuts cord and moves to area for ventilation & $56(93.3)$ & $4(6.7)$ & $49(81.7)$ & $11(18.3)$ \\
\hline $\begin{array}{l}\text { Ventilates with BM within Golden Minute at } 40 \\
\text { bpm }\end{array}$ & $55(91.7)$ & $5(8.3)$ & $52(86.7)$ & $8(13.3)$ \\
\hline Reapplies mask & $56(93.3)$ & $4(6.7)$ & $43(71.7)$ & $17(28.3)$ \\
\hline Repositions head & $49(81.7)$ & $11(18.3)$ & $48(80)$ & $12(20)$ \\
\hline Clears secretions from mouth and nose PRN & $54(90)$ & $6(10)$ & $52(86.7)$ & $8(13.3)$ \\
\hline Opens mouth slightly & $56(93.3)$ & $4(6.7)$ & $51(85)$ & $9(15)$ \\
\hline Squeezes bag harder & $55(91.7)$ & $5(8.3)$ & $53(88.3)$ & $7(11.7)$ \\
\hline $\begin{array}{l}\text { Recognizes baby is not breathing, heart rate } \\
\text { normal }\end{array}$ & $55(91.7)$ & $5(8.3)$ & $49(81.7)$ & $11(18.3)$ \\
\hline Recognizes baby is breathing, heart rate is normal & $53(88.3)$ & $7(11.7)$ & $50(83.3)$ & $10(16.7)$ \\
\hline \multirow[t]{2}{*}{$\begin{array}{l}\text { Close observation of baby, communicates with } \\
\text { mother }\end{array}$} & $54(90)$ & $6(10)$ & $52(86.7)$ & $8(13.3)$ \\
\hline & \multicolumn{2}{|l|}{21.77} & \multicolumn{2}{|l|}{19.73} \\
\hline \multicolumn{5}{|l|}{ Overall Mean scores } \\
\hline$\pm \mathbf{S D}$ & \multicolumn{2}{|l|}{1.454} & \multicolumn{2}{|l|}{2.21} \\
\hline
\end{tabular}

*Note: BM Bag and Mask; BMS Bag, Mask and Suction; SSC Skin-to-Skin Contact; 40 bpm (3050) beats per minute

*Skills items: Well done skill $=1$ point and Not done skill $=0$ point. The total score is 24

The table 2 shows the post training at day two and follow up at six week participants 'performance in HBB skills. The total means score and standard deviation among participants at day two post-training was 21.77 and 1.454 respectively. At 6week post-training the mean was 19.73 with the standard deviation of 2.21. There is a slight decrease in mean score of 2 at 6 week post-training. 
Comparison of means in knowledge and skills between the pretest, post-test at day two and follow up at six week participants 'performance

Table 3. Comparison of means in knowledge and skills between the pretest, post-test at day two and follow up at six week participants 'performance

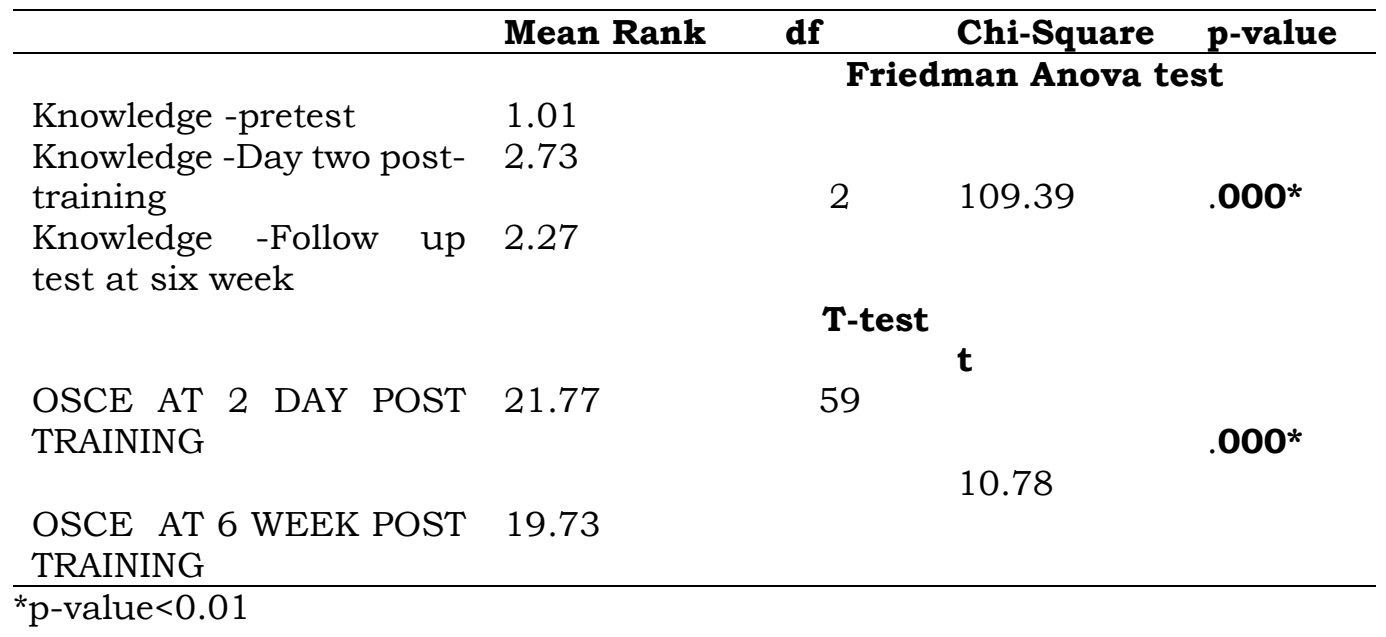

Table 3 shows the compared means between knowledge and skills in the pretest, post-test at day two and follow up at six week participants performance. There is a statistically significant difference between means pretest, day two post-training and Follow up test at six week scores with the $p$-value of $<0.01$ is found. The mean rank for day two post-training is higher that the pretest and follow up test. On skills, statistically significant difference with the p-value of $<0.01$ is found between the mean score of OSCE at 2 day post training and Follow up test at six week. That of follow up test at six weeks is higher than that of 2 days post HBB training.

Comparison of the mean score by socio-demographic characteristics of participants

Table 4.comparison of the mean score by socio-demographic characteristics

\begin{tabular}{|c|c|c|c|c|c|c|c|c|c|c|}
\hline \multirow[b]{3}{*}{ Age (years) } & \multicolumn{6}{|c|}{ KNOWLEDGE } & \\
\hline & \multicolumn{2}{|l|}{ PRETEST } & \multicolumn{2}{|c|}{$\begin{array}{l}\text { DAY } 2 \text { POST- } \\
\text { TRAINING }\end{array}$} & \multicolumn{2}{|c|}{ FOLLOW UP 6 WEEKS } & \multicolumn{2}{|c|}{$\begin{array}{l}\text { DAY } 2 \text { POST- } \\
\text { TRAINING }\end{array}$} & \multicolumn{2}{|c|}{ FOLLOW UP 6 WEEKS } \\
\hline & Mean(SD) & p-value & Mean(SD) & p-value & Mean(SD) & p-value & Mean(SD) & p-value & Mean(SD) & p-value \\
\hline$<25$ & 0.91 & 0.43 & 0.98 & 0.52 & 0.88 & & 0.98 & 0.34 & 0.87 & 0.08 \\
\hline $25-35$ & 0.93 & & 0.96 & & 0.79 & & 0.93 & & 0.90 & \\
\hline$>35$ & 0.92 & & 0.94 & & 0.90 & & 0.91 & & 0.93 & \\
\hline \multicolumn{11}{|l|}{ Gender } \\
\hline Female & $9.67(4.1)$ & 0.79 & $17.39(.6)$ & 0.10 & $16.72(1.1)$ & 0.54 & $21.50(1.5)$ & 0.41 & $19.17(2.5)$ & 0.51 \\
\hline Male & $8.36(3.9)$ & & $16.69(1.4)$ & & $16.0(1.5)$ & & $21.88(1.4)$ & & $19.98(2.0)$ & \\
\hline \multicolumn{11}{|l|}{ Education } \\
\hline A2 diploma & $7.07(4.1)$ & 0.35 & $17.33(0.6)$ & 0.15 & $16.60(1.1)$ & 0.35 & $22.13(1.0)$ & 0.10 & $20.0(2.2)$ & 0.70 \\
\hline $\begin{array}{l}\text { Advanced } \\
\text { diploma }\end{array}$ & $9.31(3.8)$ & & $16.76(1.4)$ & & $16.16(1.6)$ & & $22.13(1.5)$ & & $19.64(2.2)$ & \\
\hline $\begin{array}{l}\text { Qualification } \\
\text { Midwife }\end{array}$ & $11.50(3.4)$ & 0.32 & $16.83(1.1)$ & 0.80 & $15.83(1.4)$ & 0.95 & $22.17(.9)$ & 0.20 & $19.5(.83)$ & 0.49 \\
\hline Nurse & 8.443 .9 & & $16.91(1.3)$ & & $16.31(1.5)$ & & $21.72(1.4)$ & & $19.76(2.3)$ & \\
\hline \multicolumn{11}{|l|}{$\begin{array}{l}\text { Previous HBB } \\
\text { training }\end{array}$} \\
\hline Yes & $8.08(3.7)$ & 0.80 & $16.38(1.8)$ & $0.03 *$ & $15.54(2.0)$ & $0.04 *$ & $21.54(1.0)$ & 0.11 & $19.46(1.5)$ & 0.13 \\
\hline
\end{tabular}




\begin{tabular}{|c|c|c|c|c|c|c|c|c|c|}
\hline No & $8.94(4.0)$ & & $17.04(1.0)$ & & $16.47(1.2)$ & & 21.83 & & $19.81(2.3)$ \\
\hline \multicolumn{10}{|c|}{$\begin{array}{l}\text { Work } \\
\text { Experience } \\
\text { (years) }\end{array}$} \\
\hline$<1$ & 0.74 & 0.16 & 0.80 & 0.25 & 0.90 & 0.10 & 0.91 & 0.22 & 0.93 \\
\hline $1-5$ & 0.81 & & 0.83 & & 0.81 & & 0.85 & & 0.81 \\
\hline
\end{tabular}

${ }^{*} \mathrm{p}$-value is statistically significant if $<0.05$

Table 4 shows the comparison of socio-demographic characteristics of participants with knowledge and skills mean score before training, at 2 days and 6 weeks post-training. Only the statistically significant difference was found with $\mathrm{p}<0.05$ on knowledge at 2 days and 6 weeks post-training among participants with previous history of HBB training.

\section{DISCUSSION}

This study was conducted in four health centers in Kicukiro District, Rwanda, to assess the level of knowledge and skills among midwives and nurses. The results revealed that HBB training contributed to the increased HBB knowledge and skills and the retention was still high at six weeks after HBB training.

This study revealed that the predominant percentage $(70 \%)$ of participants was female (Table 1$)$. The majority $(60 \%)$ were young adults. Similar findings were found in a study done in the UK.[18] Also, findings of this study show that the majority of participants $(70 \%)$ had an advanced diploma level. This predominant educational level is likely related to Rwanda's changed policy to A1 being the lowest nursing school level; the lower A2 level is no longer available in the country. Among all participants, the majority $(78.3 \%)$ had not attended any HBB training. Not having attended any HBB training may be related to the lowest mean score found in the pretraining test in this study.

The pre-test knowledge scores varied, with a good overall mean score (8.75). This finding is higher compared to a study done in India, whereby nurses' pre-test knowledge mean score was 7.22.[12] Also, a study done in Nepal to assess the impact of a three-day neonatal resuscitation training, showed the pre-test knowledge score was poor.[19]

Our results showed that the knowledge and skills assessments conducted two days post-training; participants demonstrated an increased performance improvement on all knowledge and skills items. Our findings are nearly similar to those from the study in Ethiopia where results showed that participants had a higher score immediately after providing HBB training.[20] Also, a study done in Zambia found that nurses increased the level of knowledge and skills with training from $56 \%$ to $71 \%$ and $58 \%$ to $81 \%$, respectively.[21]

Also, a study to evaluate HBB post-training among midwives and nurses in Ghana, found that the level of knowledge had significantly improved from $43 \%$ to $81 \%$ for nurses, and $38 \%$ to $71 \%$ for midwives.[12] Another study showed an immediate increase in knowledge and skills scores following HBB training among nurses and doctors in India.[22]In contrast, a study conducted in Delhi, documented little improvement in the knowledge scores among nurses from 19.1 to 30.7 and skill scores from 12.8 to 20.6.[10] This finding is notably lower than the scores in the current study.

Then, compared to the day's two post-training performance, the current study showed a slight decrease in knowledge and skills performance at sixweeks post-HBB training among midwives and nurses working in four health centers in Kicukiro District. These findings correlate with the Tanzania study, which demonstrated overall strong retention of knowledge and skills among HCPs, and refresher courses were proposed to keep up-to-date knowledge and skills.[20] Similar findings were reported in a study done in India. In that study, Eblovi and colleagues [10] suggested a need for a threemonth follow-up to enhance significant retention.

A previous study conducted in Rwanda at one tertiary referral hospital and two district hospitals evaluating HBB training, knowledge was retained for three months, while skill dropped over time.[15] However, the skills dropped more than knowledge over time, which was different in the current study. The characteristics associated with deterioration of skills were associated with the lack of prior resuscitation training among care providers; and the length of follow-up tests. 
After comparing the knowledge and skills performance in pretest, day 2 and six-week post HBB training, the current study revealed the knowledge and skill performance mean difference was statistically significant different between those three times with the $p$-value $<0.01$. Our findings signify there was knowledge and skills retention among participants despite a slight drop in performance mean was found at 6 week.[19] In different studies to assess the level of knowledge and skills towards HBB training, lack of motivation, lack of refresher training and equipment for self-practice towered health care providers contributed to the decline of scores in a follow-up test.[23]

In the current study skills performance did not improve within six weeks after HBB training compared to that of day two post-training time. Our findings revealed a slight decrease on the overall mean score. Our findings are similar to that of the study done in Honduras, where a decline in skills observed after four months, a refresher course was suggested as an effective method to retain the knowledge and skills. [24] A systematic review study analyzed acquisition of knowledge and skills retention on $\mathrm{HBB}$ training in low-to-middle income countries (LMICs) had shown that a significant fall-off knowledge and skills after training and suggested a formal structured practice refresher session to improve retention. $[9,29]$

A study done in Tanzania, indicated the fall-off skills in a follow-up at four to six weeks was significant, and related contributing factors were a lack of refresher training provided at the appropriate time.[25] Hence, in the study done in Uganda about strengthening skill and knowledge retention on HBB, pre-test, and post-test, as well as a follow-up testing at one month and 12 months, the scores revealed that participant's knowledge grew significantly immediately following the training, and remain high .[14] These findings are similar to the current study; however, the scores fell by 12 months post-training.

Our findings also showed that HBB knowledge and skills was associated with having a previous HBB training. The statistically significant difference $(p<0.05)$ performance and retention was found between having a background history of HBB training and not having it. Our findings are likely similar to those of the study conducted in India, where skills retention was high among participants with previous history of HBB training.[10] According to [26] the lack of prior knowledge and refresher course is among factors and barriers to the retention of knowledge and skills on HBB.

\section{Limitations and challenges}

Findings from this study cannot be generalized because it was conducted in only one district and only four health centers from Kicukiro District. No OSCE was done in the pre-training period. The same MCQ tests were completed at the three time-points, as were the same OSCE scenarios at the two twopoints; therefore, participants could have improved their knowledge and skills by doing self-study. The knowledge and skills retention was evaluated in the short period following the HBB training.

\section{Recommendations}

Research on knowledge and skills retention at 1year post-HBB training is needed. In order to maximize HBB training outcomes, close follow ups, frequent and refresher courses are needed to guarantee sustainable retention and HBB quality practice

\section{CONCLUSION}

The study revealed there is retention of knowledge and skills six weeks after the training on HBB among midwives and nurses working in the four selected health centers in Kicukiro District. Midwives were more likely to provide care to neonates at birth; they had more knowledge and skills in pre and posttraining periods. The HBB training contributed to the increased level of HBB knowledge and skills among midwives and nurses.

\section{Author's contributions}

FK contributed to the original study, data collection, data analysis, and manuscript writing, AM and MM supervised the research study, KM assist-ed in data collection, EB and RN performed the quantitative data analysis and the manuscript draft

\section{Acknowledgments}

We acknowledge all participants that made this study successful and Bikorimana Emmanuel, who did the statistical analysis. We are also thankful to Dr. Pamela Meharry for the writing retreats and contribution to this publication.

This article is published open access under the Creative CommonsAttribution-NonCommercial NoDerivatives (CC BYNCND4.0). People can copy and redistribute the article only for noncommercial purposes and as long as they give appropriate credit to the authors. They cannot distribute any modified material obtained by remixing, transforming or building upon this article. See https://creativecommons.org/licenses/by-nc-nd/4.0/ 


\section{REFERENCES}

1. World Health Organization. Newborns: reducing mortality. 2019.

https://www.who.int/news-room/factsheets/detail/newborns-reducing-mortality

2. UNICEF. Neonatal mortality. 2019. https://data.unicef.org/topic/childsurvival/neonatal-mortality/.

3. Lissauer T, Fanaroff AA, Miall L, Fanaroff $\mathrm{J}$. Neonatology at a Glance, 3rd Edition. 2015. Wiley-Blackwell. ISBN: 978-1-118-76743-6.

4. Mendhi MM, Cartmell KB, Newman SD, Premji S, Pope C. Review of educational interventions to increase traditional birth attendants' neonatal resuscitation selfefficacy. Women and Birth. 2019 Feb 1;32(1):16-27.

5. Uwingabire F, Gowan M. Birth asphyxia at a district hospital in Kigali, Rwanda. Rwanda Journal of Medicine and Health Sciences. 2019;2(2):96-104.

6. Musafili A, Persson LÅ, Baribwira C, Påfs J, Mulindwa PA, Essén B. Case review of perinatal deaths at hospitals in Kigali, Rwanda: perinatal audit with application of a three-delays analysis. BMC pregnancy and childbirth. 2017 Dec;17(1):85.

7. Little GA, Keenan WJ, Singhal N, Niermeyer S. International perspectives: Helping Babies Breathe: Evolution of a global neonatal resuscitation program for resourcelimited areas. NeoReviews. 2014 Sep 1;15(9):e369-80.

8. Ersdal HL, Mduma E, Svensen E, Perlman JM. Early initiation of basic resuscitation interventions including face mask ventilation may reduce birth asphyxia related mortality in low-income countries: a prospective descriptive observational study. Resuscitation. 2012 Jul 1;83(7):869-73.

9. Wilson GM, Ame AM, Khatib MM, Rende EK, Hartman AM, Blood-Siegfried J. Helping B abies $B$ reathe implementation in $Z$ anzibar, $\mathrm{T}$ anzania. International journal of nursing practice. 2017 Aug;23(4):e12561.

10. Eblovi D, Kelly P, Afua G, Agyapong S, Dante S, Pellerite M. Retention and use of newborn resuscitation skills following a series of helping babies breathe trainings for midwives in rural Ghana. Global health action. 2017 Jan 1;10(1):1387985.

11. Draiko CV, Yamarat K, Panza A, Draleru J. Knowledge, skills and competency retention among health workers one year after completing helping babies breathe training in South Sudan. The Pan African Medical Journal. 2019;33.

12. Kamath-Rayne BD, Thukral A, Visick MK, Schoen E, Amick E, Deorari A, Cain CJ, Keenan WJ, Singhal N, Little GA, Niermeyer S. Helping babies breathe: a model for strengthening educational programs to increase global newborn survival. Global Health: Science and Practice. 2018 Oct 3;6(3):538-51.

13. Ndzima-Konzeka FF. The knowledge of basic neonatal resuscitation among midwives at district hospitals (Doctoral dissertation, Stellenbosch: Stellenbosch University).June,2017.

14. Tabangin ME, Josyula S, Taylor KK, Vasquez JC, Kamath-Rayne BD. Resuscitation skills after Helping Babies Breathe training: a comparison of varying practice frequency and impact on retention of skills in different types of providers. International health. 2018 May 1;10(3):163-71.

15. Bang A, Patel A, Bellad R, Gisore P, Goudar SS, Esamai F, Liechty EA, Meleth S, Goco N, Niermeyer S, Keenan W. Helping Babies Breathe (HBB) training: What happens to knowledge and skills over time?. BMC pregnancy and childbirth. 2016 Dec;16(1):364.

16. Isangula KG, Kassick ME, Kairuki AK, Meda RA, Thomas E, Temu A, Msemo G, Azayo M, Nelson BD. Provider experiences with the large-scale 'Helping Babies Breathe'training programme in Tanzania. Paediatrics and international child health. 2018 Jan 2;38(1):46-52.

17. American Academy of Pediatrics. Helping Babies Breathe (2nd Edition). https://www.aap.org/en-us/advocacy-andpolicy/aap-health-initiatives/helpingbabies-survive/Pages/Helping-BabiesBreathe-Edition.aspx

18. Macfarlane KA, Bruce LE. G282 (P) 259 
Educational outcomes of helping babies breathe training in rural rwanda. Archives of Disease in Childhood. 2019 May 1;104(Suppl 2):A115.

19. Ashish KC, Wrammert J, Nelin V, Clark RB, Ewald U, Peterson S, Målqvist M. Evaluation of Helping Babies Breathe Quality Improvement Cycle (HBB-QIC) on retention of neonatal resuscitation skills six months after training in Nepal. BMC pediatrics. 2017 Dec;17(1):103.

20. Drake M, Bishanga DR, Temu A, Njozi M, Thomas E, Mponzi V, Arlington L, Msemo G, Azayo M, Kairuki A, Meda AR. Structured on-the-job training to improve retention of newborn resuscitation skills: a national cohort Helping Babies Breathe study in Tanzania. BMC pediatrics. 2019 Dec;19(1):51.

21. Mistry SC, Lin R, Mumphansha H, Kettley LC, Pearson JA, Akrimi S, Mayne DJ, Hangoma W, Bould MD. Newborn Resuscitation Skills in Health Care Providers at a Zambian Tertiary Center, and Comparison to World Health Organization Standards. Anesthesia \& Analgesia. 2018 Jul 1;127(1):217-23.

22. Kumar DS, Chetna C, Singh BS, Arti M, Ashish J, Kumar KS, et al. Retention of Knowledge and Skill of Birth Attendants in Newborn Care and Resuscitation after 1 Year in Clinical Practice: An Experience from India. Journal of Clincial Neonatalogy, 2018;7(2):89-95.

23. Reisman J, Arlington L, Jensen L, Louis H, Suarez-Rebling D, Nelson BD. Newborn resuscitation training in resource-limited settings: a systematic literature review. Pediatrics. 2016 Aug 1;138(2):e20154490.
24. Seto TL, Tabangin ME, Josyula S, Taylor KK, Vasquez JC, Kamath-Rayne BD. Educational outcomes of Helping Babies Breathe training at a community hospital in Honduras. Perspectives on medical education. 2015 Oct 1;4(5):225-32.

25. Arlington L, Kairuki AK, Isangula KG, Meda RA, Thomas E, Temu A, Mponzi V, Bishanga D, Msemo G, Azayo M, Nelson BD. Implementation of "Helping Babies Breathe": a 3-year experience in Tanzania. Pediatrics. 2017 May 1;139(5):e20162132.

26. Mildenberger C, Ellis C, Lee K. Neonatal resuscitation training for midwives in Uganda: Strengthening skill and knowledge retention. Midwifery. 2017 Jul 1;50:36-41.

27. Arabi AM, Ibrahim SA, Ahmed SE, MacGinnea F, Hawkes G, Dempsey E, Ryan CA. Skills retention in Sudanese village midwives 1 year following Helping Babies Breathe training. Archives of disease in childhood. 2016 May 1;101(5):439-42.

28. Horiuchi S, Rattana S, Saysanasongkham B, Kounnavongsa O, Kubota S, Cayrol J, Takahashi K, Inoue M, Nemoto A, Yamaoka K. Study protocol of a cluster randomized controlled trial to evaluate effectiveness of a system for maintaining high-quality early essential newborn care in Lao PDR. BMC health services research. 2018 Dec $1 ; 18(1): 489$.

29. Tabangin ME, Josyula S, Taylor KK, Vasquez JC, Kamath-Rayne BD. Resuscitation skills after Helping Babies Breathe training: a comparison of varying practice frequency and impact on retention of skills in different types of providers. International health. 2018 May 1;10(3):163-71. 